\title{
Modeling of Volatile Organic Compounds Condensation in a Vertical Tube
}

\author{
Kaoutar Zine-Dine*, Youness El Hammami, Rachid Mir, Sara Armou, Touria Mediouni \\ Laboratory of Mechanics, Processes, Energy and Environment, Ibn Zohr University, ENSA, B.P 1136, Agadir, Morocco
}

Corresponding Author Email: zinedinekaouthar@gmail.com

https://doi.org/10.18280/ijht.370202

Received: 20 November 2018

Accepted: 21 April 2019

\section{Keywords:}

condensation process, heat and mass transfer, numerical simulation, phase change, ternary mixture

\begin{abstract}
The aim of this numerical study is to investigate the heat and mass transfer during the volatile organic compounds (VOCs) condensation, particularly alcohols (n-butanol-propanol, ethanolpropanol and n-butanol-ethanol) in the presence of air along a vertical tube. The parabolic governing equations coupled in the both liquid and gas phases with the appropriate boundary and interfacial conditions are solved by an applied numerical method. Thomas algorithm solves the systems of equations, obtained using an implicit finite differences method. The numerical results obtained indicate that the thermal and mass transfer is more intense at the inlet of tube for the three mixtures thus favoring thermal and mass exchanges and the Nusselt number is higher for the ethanol-propanol mixture compared to other mixtures.
\end{abstract}

\section{INTRODUCTION}

VOCs are atmospheric pollutants that have a negative impact on health and ecosystems and are linked to the greenhouse effect and global warming. Hence the necessity to reduce their concentration in the atmosphere and particular in the industrial discharges. There are several reduction techniques for these compounds, the most common of which are absorption treatment, adsorption treatment, condensation treatment and membrane treatment. The technique of VOC capture by condensation is based on the simple principle of liquid-vapor equilibrium of a ternary mixture (VOC-air).

For multicomponent mixtures condensation, studies have shown that the diffusive flux of an element does not depend only on its concentration gradient, but depends on the concentration gradients of all solution species Toor [1-2]. Mirkovich and Missen [3] have studied mixtures formed from n-pentane, methanol and dichloromethylene as well as npentane, n-hexane. Their test geometry was a vertical tube with $150 \mathrm{~mm}$ in the diameter which can be considered as a flat plate. Their first studies were to visualize the profile of the condensate film. With the two dichloromethylene-methanol and n-pentane-n-hexane binary mixtures, they have observed a smooth laminar film for all concentrations tested. On the other hand, the n-pentane-methanol and n-pentanedichloromethylene mixtures produce different condensation modes depending on the composition and the exchanged flux. For concentrations close to pure fluids and azeotropic mixtures or for high fluxes, they still visualized a smooth laminar film. But, in the case of higher concentrations, by reducing the exchanged flux, they saw waves appear which progressively cover the laminar film. Bandrowski and Bryczkowski [4] presented an experimental study on the binary and ternary mixtures condensation based on methanol, n-propanol and water on a smooth tube and have established appropriate correlations. A numerical study of the condensation of multicomponent mixture (methanol-water-air and acetonemethanol-water) on a vertical plate with constant wall is developed by Taitel and Tamir [5]. This theory is based only on conservation equations. The results are obtained by two different methods: the exact resolution of the conservation equations and the approximate integral method. They have shown that the temperature at the liquid-vapor interface becomes lower than the temperature of the mixture. This is caused by the accumulation of non-condensable gas at the interface and the more volatile components, which reduces the condensation rate. Braun and Renz [6] presented a numerical study of the heat and mass transfer during a ternary mixture condensation in laminar and turbulent flow inside a vertical tube. The results show that the effects of the multicomponent diffusion interactions on the mass fraction profiles are demonstrated at the osmotic diffusion point of a component during the condensation of two components.

An experimental study developed by Fujii et al. [7] on mixtures obtained from water, ethanol and methanol has brought interesting results. The condensation of the ethanolmethanol binary mixture forms a film whereas; the other two binary mixtures develop different modes of condensation. The methanol-water mixture condenses in the form of drops while the ethanol-water mixture takes successively the aspects of film, waves and drops. The result of these observations and measurements shows that the exchange coefficient of the condensation in drops can be up to 6 times higher than the theoretical coefficient of a film condensation. However, this increase is less than that which can be expected for the drop condensation of a pure fluid. The resistance due to diffusion in the vapor phase must certainly attenuate this gain.

El Hammami et al. [8] developed a numerical study of heat and mass transfer during the condensation of water vapor and ethanol (and methanol) mixture in the presence of air. They showed that the transfers during the condensation of the ethanol vapor and methanol mixture are more influenced by the non-condensable gas compared to the water vapor.

A numerical study of the effects of non-condensable gas type in a vapor mixture of water-gas (water vapor- Neon, water vapor- Air, water vapor- Argon, and water vapor- Krypton ) during the condensation along a vertical tube with a wall subjected to a non uniform flow is investigate by Zine-Dine et 
al. [9]. They have shown that the increase of molar mass of non-condensable gases influences on the thermal and mass transfer.

The results of the calculation model were validated with those in the literature to verify the accuracy of the numerical procedure developed [9]. The comparison is made with numerical study of Hassaninejadfarahani et al. [10]. The numerical results are also compared by the experimental study of Lebedev et al. [11] during vapor humid air condensation.

The purpose of this work is to reduce the concentration of volatile organic compounds (n-butanol-propanol-air, ethanolpropanol-air and n-butanol-ethanol-air), by condensation; given their usefulness in the pharmaceutical industry, food, refining of oil and in means of transport. These VOCs have acute toxicity in humans and animals (causes skin irritation, serious eye damage, can irritate the respiratory tract ...), they also have impacts on the environment (they intervene in the formation of tropospheric ozone and contribute to the phenomenon of acid rain attacking plants and buildings).

\section{PHYSICAL AND MATHEMATICAL MODELLING}

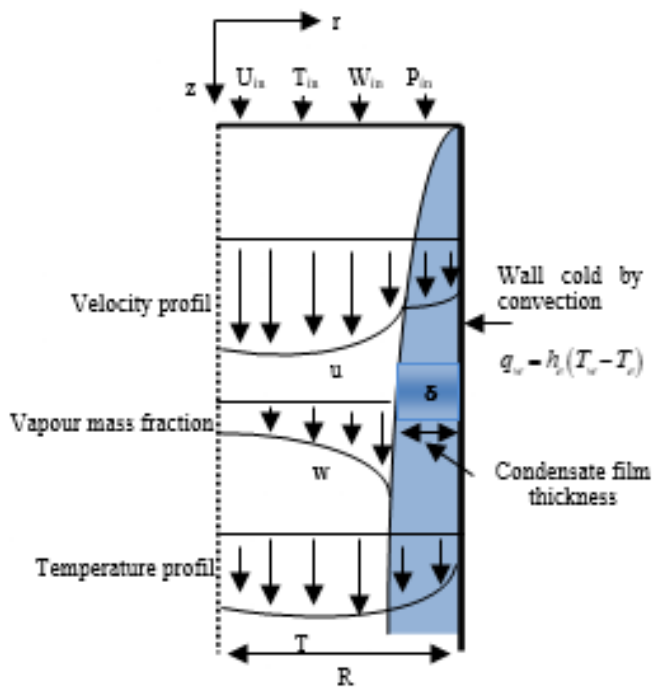

Figure 1. Physical model

The physical model of the problem studied is a vertical tube with length $\mathrm{L}$, radius $\mathrm{R}$, and thickness $\delta \mathrm{z}$ which very low compared to R (Figure 1). The tube wall is subjected to a nonuniform flow (i.e, cooled by a flow air at temperature $T_{e}$ ). The flow of the vapor-gas mixture is laminar and symmetrical about the centre line of the tube. At the inlet tube arrive a flow of vapor mixture and a non-condensable gas at a uniform temperature $T_{\text {in }}$, uniform pressure $P_{i n}$, uniform velocity $u_{\text {in }}$ and vapor mass fraction $w_{i n}$. The following assumptions were made for the mathematical formulation:

- The flow of gas mixture is stationary, laminar, incompressible and two dimensional.

- Boundary layer approximations are used for both phases.

- The Radiative heat transfer and viscous dissipation are not taken into account.

- The vapor-liquid interface is movable, without waves and in thermodynamic equilibrium,

- The effect of the liquid superficial tension is not taken into account.
Considering the above assumptions, the set of governing equations corresponding to the continuity, momentum, energy, concentration and the boundary conditions, for both gas and liquid film are written in the following form:

\subsection{Liquid film}

Continuity equation:

$$
\frac{\partial}{\partial z}\left(\rho_{l} u_{l}\right)+\frac{1}{r} \frac{\partial}{\partial r}\left(r \rho_{l} v_{l}\right)=0
$$

Momentum equation:

$\frac{\partial}{\partial z}\left(\rho_{l} u_{l}^{2}\right)+\frac{1}{r}\left(\frac{\partial}{\partial r}\left(\rho_{l} r v_{l} u_{l}\right)\right)=-\frac{d p}{d z}+\frac{1}{r} \frac{\partial}{\partial r}\left(r u_{l} \frac{\partial u_{l}}{\partial r}\right)+\rho_{l} g$

Energy equation:

$$
\frac{\partial}{\partial z}\left(\rho_{l} C_{p}^{l} u_{l} T_{l}\right)+\frac{1}{r} \frac{\partial}{\partial r}\left(\rho_{l} C_{p}^{l} r v_{l} T_{l}\right)=\frac{1}{r} \frac{\partial}{\partial r}\left(r \lambda_{l} \frac{\partial T_{l}}{\partial r}\right)
$$

\subsection{Gas mixture}

Continuity equation:

$$
\frac{\partial}{\partial z}\left(\rho_{m} u_{m}\right)+\frac{1}{r} \frac{\partial}{\partial r}\left(r \rho_{m} v_{m}\right)=0
$$

Momentum equation:

$\frac{\partial}{\partial z}\left(\rho_{m} u_{m}^{2}\right)+\frac{1}{r}\left(\frac{\partial}{\partial r}\left(\rho_{m} r v_{m} u_{m}\right)\right)=-\frac{d p}{d z}+\frac{1}{r} \frac{\partial}{\partial r}\left(r u_{m} \frac{\partial u_{m}}{\partial r}\right)+\rho_{m} g$

Energy equation:

$$
\begin{aligned}
& \frac{\partial}{\partial z}\left(\rho_{m} C_{p}^{m} u_{m} T_{m}\right)+\frac{1}{r} \frac{\partial}{\partial r}\left(\rho_{m} C_{p}^{m} r v_{m} T_{m}\right)=\frac{1}{r} \frac{\partial}{\partial r}\left(r \lambda_{m} \frac{\partial T_{m}}{\partial r}\right)+ \\
& \frac{1}{r} \frac{\partial}{\partial r}\left[r \rho_{m} D\left(C_{p v}-C_{p g}\right)\right] \frac{\partial W^{k}}{\partial r} T_{m}
\end{aligned}
$$

Diffusion equation:

$$
\begin{gathered}
\frac{\partial}{\partial z}\left(\rho_{m} u_{m} W^{k}\right)+\frac{1}{r} \frac{\partial}{\partial r}\left(\rho_{m} r v_{m} W^{k}\right)=\frac{1}{r} \frac{\partial}{\partial r}\left(r \rho_{m} D \frac{\partial W^{k}}{\partial r}\right) \\
\mathrm{K}=1,2
\end{gathered}
$$

It is necessary to add the mass conservation equation in both liquid and gas phases to the previous system, in order to complete the mathematical modeling of the problem.

So the global mass conservation can be expressed as follows:

$$
\frac{\dot{m_{i n}}}{2 \pi}=\int_{0}^{R-\delta_{z}} r \rho_{m} u_{m} d r+\int_{R-\delta_{z}}^{R} r \rho_{l} u_{l} d r
$$

The pure component data are approximated by polynomials in term of temperature and mass fraction. For further details, 
the thermophysical properties are available in Fuller [12], Perry Don [13], Bromley and Wilke [14].

\subsection{Boundary and interface conditions}

The imposed boundary and interface conditions are the followings:

- Condition at the inlet of the tube $z=0$ :

$$
u_{m}=u_{i n} \quad T_{m}=T_{i n} \quad W=W_{i n} \quad p_{m}=p_{i n}
$$

- Condition on the central axis of the tube $r=0$ :

$$
\frac{\partial u_{m}}{\partial r}=\frac{\partial T_{m}}{\partial r}=\frac{\partial W}{\partial r}=0 \quad \quad \mathrm{v}_{\mathrm{m}}=0
$$

- Condition on the tube wall $\mathrm{r}=\mathrm{R}$

$$
q_{m}=-\left.\lambda_{l} \frac{\partial T_{l}}{\partial r}\right|_{w}=h_{e}\left(T_{w}-T_{e}\right) \quad \mathrm{u}_{1}=v_{l}=0
$$

- Interfacial conditions $\mathrm{r}=\mathrm{R}-\delta_{\mathrm{z}}$

Continuities of velocity and temperature:

$$
u_{I}(z)=u_{m, I}=u_{l, I} \quad \mathrm{~T}_{\mathrm{I}}(z)=T_{m, I}=T_{l, I}
$$

Continuities of the shear stress and heat flux:

$$
\tau_{I}=\left[\mu \frac{\partial u}{\partial r}\right]_{l, I}=\left[\mu \frac{\partial u}{\partial r}\right]_{m, I}
$$

The total convective heat flux from the film interface to the gas stream can be expressed by sensitive mode $\mathrm{Q}_{\mathrm{sen}, \mathrm{I}}$ and latent mode $\mathrm{Q}_{\text {Lat, } \mathrm{I}}$ as follows:

$$
Q_{I}=Q_{s e s, I}+Q_{L a t, I}=-\lambda_{m} \frac{\partial T_{m}}{\partial r}+\dot{m}_{I} h_{f g}
$$

The interfacial mass flux exchanged between the two phases is determined by Fick's law as follows

$$
\dot{m}_{I}=-\frac{\rho_{m} \sum_{k=1}^{2}\left(D_{k}^{m} \frac{\partial W}{\partial r}\right)_{I}}{1-\sum_{k=1}^{2} W_{I}^{k}}
$$

The interfacial mass fraction can be calculated as follows:

$$
W_{I}^{k}=\frac{P_{k I} M_{k}}{\sum_{i=1}^{3} P_{i} M_{i}}
$$

Along the interface the local Nusselt and Sherwood numbers are given by the following expressions:

$$
N u_{z}=\frac{h_{t}(2 R)}{\lambda_{m}}=\frac{Q_{I}(2 R)}{\lambda_{m}\left(T_{b u l k}-T_{I}\right)}
$$

$$
S h_{z}=\frac{h_{M}(2 R)}{D}=\frac{m_{I}\left(1-W_{I}\right)(2 R)}{\rho_{m} D\left(W_{b u l k}-W_{I}\right)}
$$

$\mathrm{T}_{\text {bulk }}$ and $\mathrm{W}_{\text {bulk }}$ are respectively the temperature and mass fraction of the bulk, which are defined as follows:

$$
T_{\text {bulk }}=\frac{\int_{0}^{R-\delta} \rho_{m} C_{p}^{m} r u_{m} d r}{\int_{0}^{R-\delta} \rho_{m} C_{p}^{m} r u_{m} d r} \quad W_{\text {bulk }}=\frac{\int_{0}^{R-\delta} \rho_{m} r u_{m} W d r}{\int_{0}^{R-\delta} \rho_{m} r u_{m} d r}
$$

The total condensate rate defined by the expression:

$$
M_{r}=\frac{2 \pi \int_{0}^{z}\left(R-\delta_{z}\right) m_{I} d z}{m_{\text {in }}}
$$

\section{NUMERICAL RESOLUTION METHOD}

\subsection{Solution method}

Given the impossibility of obtaining an analytical method for the non-linear coupling differential equations, the conjugated problem leading to the parabolic system of equation (1) - (7) with the appropriate boundary conditions are solved by a finite difference numerical scheme. The transversal convection and diffusion terms are approximated by the central difference while the axial convection terms are approximated by the backward difference. In the centerline ( $\mathrm{r}$ $=0$ ) of the tube, the diffusional terms are singular. A correct representation can be found from an application of L'Hospital's rule. Each system of the finite-difference equations forms a tridiagonal matrix equation, which can be solved by the TDMA Method Patankar [15].

\subsection{Velocity and pressure coupling}

The problem of coupling velocity-pressure is manifested by the appearance of these variables in the momentum equation. The pressure gradient $\frac{d P_{d}}{d z}$ which appears as the source term in this equation plays the role of the flow motor. Unfortunately, no pressure equation is available. Also, pressure is always an unknown to determine as well as velocity. A given velocity field can satisfy the continuity equation without checking the momentum transport equations. This peculiarity of equations necessitates the use of a velocity-pressure coupling algorithm.

Several types of iterative procedures can be used. In this study we use the method of Raithby and Schneider [16] who proposed an appropriate arrangement for incompressible flows that requires one third less effort (three iterations) than the calculation of the secant. The iterative procedure of this method can be summarized as follows:

Given $\left(\frac{d P_{d}}{d z}\right)^{*}$, taking account of the momentum quantity equation, a solution temporary $\mathrm{u}^{*}$ is obtained. In this step, the mass flow rate of the flow is defined as follows: $\dot{m}^{*}=$ $\int \rho u^{*} d r$.

The arrangement of the momentum equation assumes that the coefficients in the discretized equations will remain 
constant, i.e., no form of the update is used while the pressure gradient is adjusted so that the overall stress of the mass flow is satisfied. A correction can be obtained using a form of the Newton method. With the "frozen" coefficients, the velocities vary linearly with the pressure gradient, so Newton's method should provide the pressure gradient correction. To illustrate this correction, we put:

$$
Q=\left(\frac{d P_{d}}{d z}\right)^{*} \quad \text { and } \quad \mathrm{F}_{\mathrm{p}}=\frac{\partial u_{p}}{\partial Q}
$$

The integration of equation (21) leads to:

$$
\begin{aligned}
& u_{p}=u_{p}^{*}+F_{p} \Delta Q \\
& \text { with } \quad \Delta \mathrm{Q}=-\left[\frac{\partial \mathrm{P}_{\mathrm{d}}}{\partial \mathrm{z}}-\left(\frac{\partial P_{d}}{\partial z}\right)^{*}\right]
\end{aligned}
$$

The integration of equation (21) makes it possible to obtain the pressure gradient difference as follows:

$$
\Delta Q=\frac{m-m^{*}}{\int \rho F_{P} d r}
$$

which give:

$$
\left(-\frac{d P_{d}}{d z}\right)=\frac{\dot{\mathrm{m}}-\dot{m}^{*}}{\int \rho F_{p} d r}+\left(-\frac{\partial \mathrm{P}_{\mathrm{d}}}{\partial \mathrm{z}}\right)^{*}
$$

In equation (24), $\dot{m}$ is a known value indicated by the initial conditions. This requires determination of $\left(-\frac{\partial P_{d}}{\partial z}\right)$. The corrected velocity up values can then be determined from equation (22). The continuity equation is then used to determine vp.

\subsection{Calculation of liquid film thickness}

The film liquid thickness is variable along the flow. At each section $\mathrm{z}$, it is calculated by the secant method Nougier J.P. [17] applied to the mass flow conservation equation of total condensate, according to the following iterative procedure:

- We impose two arbitrary distinct values from the film thickness and

- For each of them, iteratively resolves the momentum, continuity, energy and diffusion equations successively until convergence is verified according to criterion:

$$
\operatorname{Max}\left|\frac{\phi_{i, j}^{n}-\phi_{i, j}^{n-1}}{\phi_{i, j}^{n-1}}\right| \prec 10^{-6} \quad \phi: \mathrm{u}, \mathrm{T} \text { et } \mathrm{W}
$$

- The relative error En is then calculated on the mass flow rate of condensate.

- From the $3^{\text {rd }}$ iteration ( $n \geq 3$ ), if the relative error is greater than $10^{-6}$, then another value of is calculated by the secant method as follows:

$$
\delta_{z}^{n}=\delta_{z}^{n-1}-\mathrm{E}^{\mathrm{n}-1}\left(\frac{\delta_{\mathrm{z}}^{\mathrm{n}-1}-\delta_{z}^{n-2}}{E^{n-1}-E^{n-2}}\right)
$$

- Otherwise, the value $\delta_{z}^{n}$ obtained is adopted and we go to the next line.

\subsection{Stability of the calculation scheme}

In order to choose the computational grid for the numerical simulation, a preliminary test had been conducted. To refine the numerical calculation, a non-uniform grid was been chosen, based on geometrical progression in the radial and axial directions and taking into account the irregular variation of $\mathrm{u}$, $\mathrm{T}$ and $\mathrm{W}$ at the gas-liquid interface and at the tube entrance. As a result, the density of the nodes is greater at the gas-liquid interface and at entrance. The variation of the local Nusselt and Sherwood numbers are calculated for each grid size (axial direction (I) and the radial direction, respectively in the gas (J) and liquid (K)) as shown in Table 1 . The results show that, the relative error does not exceed $3 \%$ for the variations of the local Nusselt and Sherwood numbers, related to computations using grids ranging from $51 *(81+21)$ to $201 *(121+81)$. In view of these results all further calculations presented in this paper were performed with the $131 *(81+31)$ grid.

Table 1. Comparisons of local Nusselt and Sherwood numbers at the interface for various grids $\left(\mathrm{p}_{\mathrm{in}}=1 . \operatorname{atm}, \mathrm{Re}_{\mathrm{in}}=2000, \mathrm{H}_{\mathrm{r}}=50 \%\right.$ and $\mathrm{T}_{\mathrm{in}}=60^{\circ} \mathrm{C}$ )

\begin{tabular}{|c|c|c|c|c|c|c|}
\hline \multicolumn{9}{|c|}{$\mathrm{I}^{*}(\mathrm{~J}+\mathrm{K})$} \\
\hline $\mathrm{z} / \mathrm{L}$ & & $51 *(81+21)$ & $101 *(61+31)$ & $131^{*}(81+31)$ & $201 *(81+51)$ & $201 *(121+81)$ \\
\hline \multirow{2}{*}{0.0470} & $\mathrm{Nuz}$ & 21.69 & 21.30 & 20.70 & 20.75 & 20.81 \\
\cline { 2 - 7 } & Shz & 9.741 & 9.282 & 9.290 & 9.279 & 9.281 \\
\hline \multirow{2}{*}{0.3498} & $\mathrm{Nuz}$ & 13.70 & 13.71 & 13.70 & 13.70 & 13.69 \\
\cline { 2 - 7 } & Shz & 5.591 & 5.583 & 5.571 & 5.570 & 5.580 \\
\hline 0.5559 & $\mathrm{Nuz}$ & 12.30 & 12.31 & 12.30 & 12.30 & 12.30 \\
\cline { 2 - 7 } & Shz & 5.160 & 5.168 & 5.160 & 5.162 & 5.161 \\
\hline 0.7531 & $\mathrm{Nuz}$ & 11.35 & 11.39 & 11.36 & 11.39 & 11.40 \\
\cline { 2 - 7 } & Shz & 4.952 & 4.965 & 4.950 & 4.96 & 4.96 \\
\hline \multirow{2}{*}{1.00} & $\mathrm{Nuz}$ & 10.51 & 10.53 & 10.51 & 10.54 & 10.55 \\
\cline { 2 - 7 } & Shz & 4.801 & 4.815 & 4.808 & 4.818 & 4.818 \\
\hline
\end{tabular}

\section{RESULTS AND DISCUSSION}

A study was realized to analyze the ternary mixture condensation of volatile organic compounds in particular the alcohols (Ethanol, Propanol and n-Butanol) in the presence of air. The calculations were performed for a vertical tube of 
length $\mathrm{L}=2 \mathrm{~m}$ and $\mathrm{d}=2 \mathrm{~cm}$ in diameter, the tube wall is cooled by a flow air at temperature $T_{e}$.

In order to make a comparison of the three ternary mixtures condensation, the results of this section are presented around the following nominal values:

- Temperature difference between inlet and external is $\Delta \mathrm{T}=30{ }^{\circ} \mathrm{C}$,

- The Reynolds number is $\mathrm{Re}_{\mathrm{in}}=2000$,

- The inlet pressure is $P_{\text {in }}=1 \mathrm{~atm}$,

- The mass fraction of the constituents at the input: $W_{\text {in }}^{n-b u \tan o l}=0.05$ and $W_{\text {in }}^{\text {propanol }}=W_{\text {in }}^{\text {ethanol }}=0.25$.
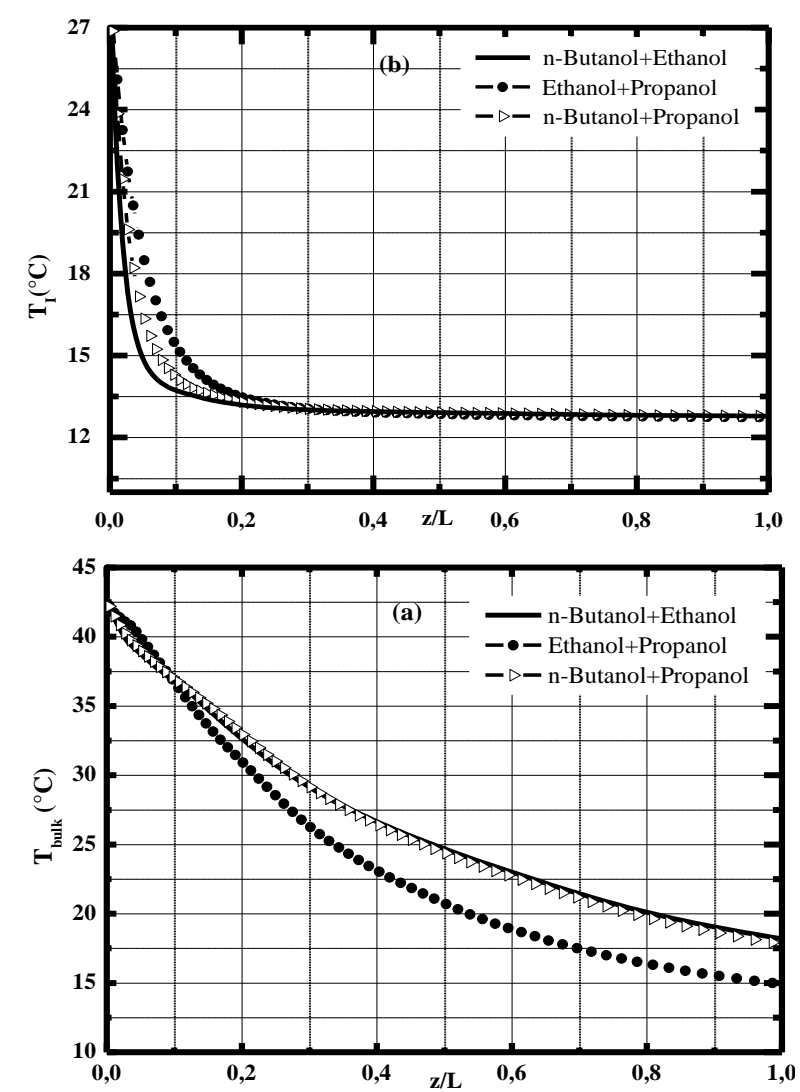

Figure 2. Variation of bulk temperature (a) and interface temperature (b) along the tube

Figure 2 shows variation of the bulk temperature $\mathrm{T}_{\text {bulk }}$ and the interface $T_{I}$ along the tube for three ternary mixtures. It is noted that for the three fluids, interface temperature $T_{I}$ decreases to tend towards the cooling temperature of the external fluid (Figure $2(\mathrm{~b})$ ), and that beyond $0.3(\mathrm{z} / \mathrm{L} \geq 0.3)$ the interface temperatures of the three mixtures are confounded and become constant because it reached the end of condensation. For the bulk temperature $\mathrm{T}_{\text {bulk }}$, it decreases along the tube, tending towards the interface temperature (Figure 2 (a)). The length of the tube used does not allow in that case joining the interface temperature.

It is noted on these results, that at the inlet of tube, the curve of ethanol-propanol interface temperature is above n-butanolpropanol which is itself above that of the n-butanol-ethanol. The explanation of this order come from the fact that the three mixtures contain at least one constituent having the same concentration at $25 \%$, the interface temperature then corresponds to the saturation temperature of these constituents (ethanol: $42.70{ }^{\circ} \mathrm{C}$., propanol: $42.18{ }^{\circ} \mathrm{C}$, n-butanol: $38.93{ }^{\circ} \mathrm{C}$ ).

To analyze the heat transfer during the volatile organic compounds condensation along the tube, it is necessary to determine the Nusselt number which globally reflects the evolution of the flow ratio convective and conductive along the tube.

Figure 3 shows that the local Nusselt number is important at the inlet, this is due to the important thermal gradient in this zone, because of the temperature difference between the inlet vapor $\left(42^{\circ} \mathrm{C}\right)$ and the liquid film $\left(27^{\circ} \mathrm{C}\right)$ (see Figure 2$)$.

Transfers are therefore more intense at the tube inlet for the three mixtures thus promoting heat and mass exchange. The heat released by the liquid to vapor has a part by latent heat due to condensation of vapor, and a part by sensible heat due to liquid-vapor contact. The condensation heat decreases due to decreasing of condensed quantities because the steam becomes poorer as one advance in the tube. The exchange by sensible heat also decreases because of the approximation of the temperatures of the gas and the liquid. The local Nusselt number (Figure 3) therefore decreases as the flow progresses in the tube. At the exit the three curves meet at the end of condensation.

Note that $\mathrm{Nu}_{\mathrm{z}}$ is more important for ethanol-propanol mixture compared to other mixtures, this is due to the fact that on one hand the amount of this mixture is greater $(50 \%)$ and on the other hand its heat latent which is larger $(831.14 \mathrm{J.Kg}$ $\left.{ }^{1}\right)$ than that of n-butanol-ethanol and n-butanol-propanol (792.89 J. Kg $\left.{ }^{-1}\right)$; (728.02 J. Kg-1).

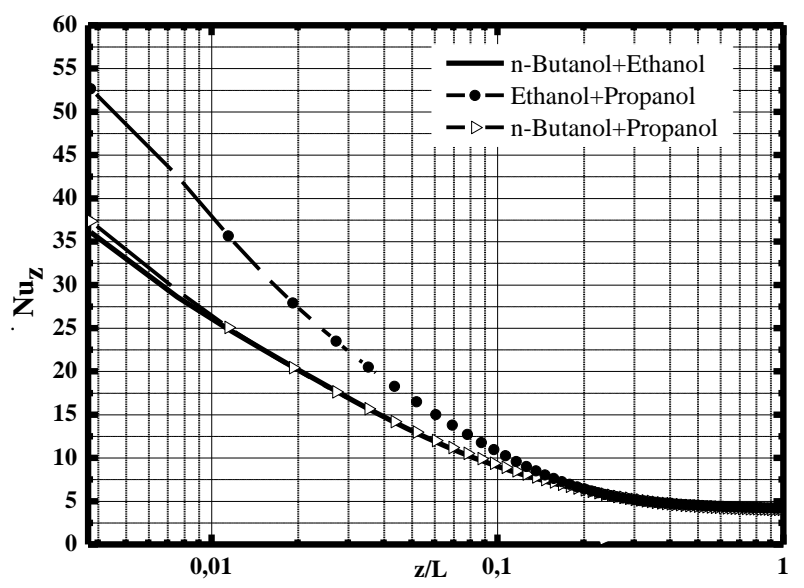

Figure 3. Variation of Nusselt number along the tube for the three ternary mixtures

Figures 4 (a), (b) show the variation of bulk mass fraction $\mathrm{W}_{\text {bulk }}$ and interface $\mathrm{W}_{\mathrm{I}}$ along the tube. The interface mass fraction $\mathrm{W}_{\mathrm{I}}$ follow the evolution of the interface temperature $\mathrm{T}_{\mathrm{I}}$, they decrease along the tube to establish a fixed level. The bulk mass fraction $\mathrm{W}_{\text {bulk }}$ similarly decreases to reach the end of $\mathrm{W}_{\mathrm{I}}$ for the three mixtures (Figure 4 (a)). It is found that the mass fraction of ethanol vapor is higher compared with that of propanol and n-butanol. As for the comparison with n-butanol, the explanation is due to small quantity of n-butanol injected at the inlet. As regards the propanol, which is injected with the same concentration as ethanol, the cause is its saturation pressure and therefore its saturation temperature, which is lower than that of ethanol. Its liquefaction is therefore slightly behind with ethanol.

Figure 5(a) illustrates the variation of the liquid film thickness along the tube for the three ternary mixtures (nbutanol-propanol-air, ethanol-propanol-air and n-butanolethanol-air). 

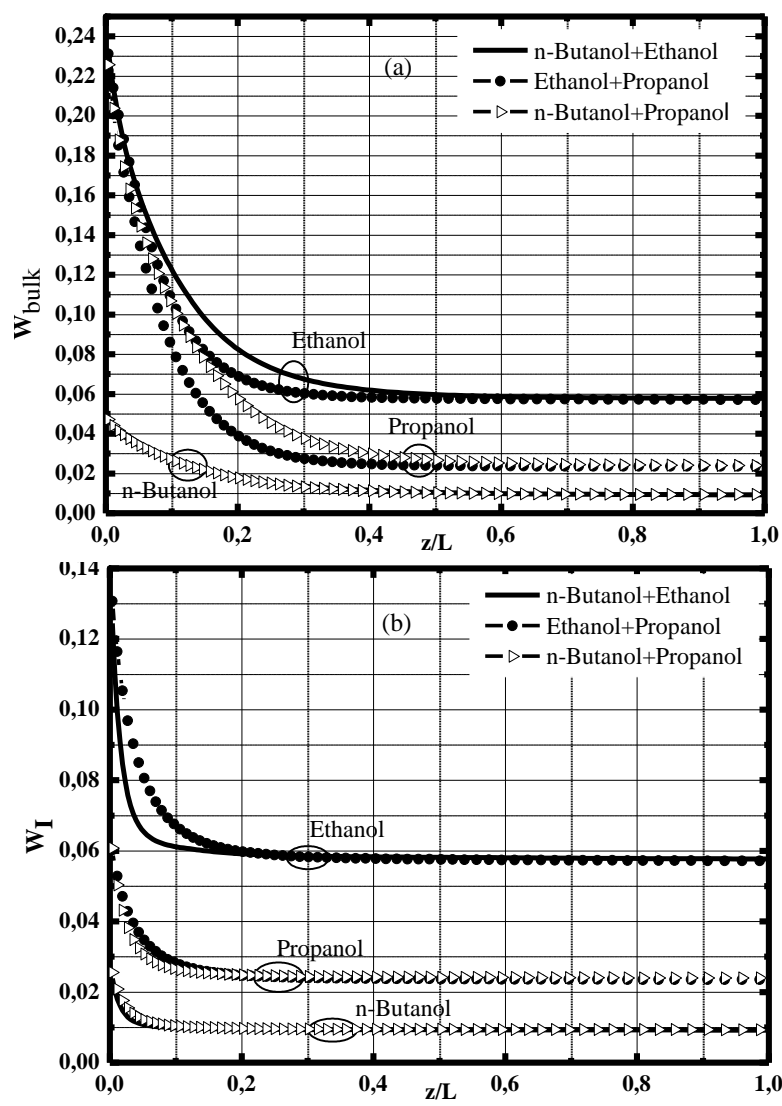

Figure 4. Variation of bulk mass fraction (a) and interface (b) along the tube

It is noted that the liquid film thickness increases as the flow of vapor mixture progresses in the tube, and becomes constant for values $z / L \geq 0.3$. This is explained by the bulk temperature $\mathrm{T}_{\text {bulk }}$ which becomes very close to the interface temperature $T_{I}$ therefore the end of condensation is reached. It is observed that the liquid film thickness is important for the n-butanol propanol mixture. This difference in behavior is explained by the viscosity of the n-butanol propanol mixture $\left(\mu_{\mathrm{Liq}}=2.053 * 10^{-3} \mathrm{Kg} \cdot \mathrm{m}-1 . \mathrm{s}^{-1}\right)$ which is greater than that of ethanol-propanol $\left(\mu_{\mathrm{Liq}}=1.31 * 10^{-3} \mathrm{Kg} \cdot \mathrm{m}^{-1} . \mathrm{s}^{-1}\right)$ therefore its velocity is lower than that of ethanol-propanol hence the film thickness is greater. Indeed, when the viscosity increases, the friction forces increase consequently the effect of the friction increases. Figure 5(b) shows that the condensation rate of ethanol-propanol mixture is higher than the condensation rate of the n-butanol-propanol mixture and at the end of condensation, they are almost confused. Indeed these results confirm the results of Figure 4(a).

Figure 6 shows the variation of the condensed rate along the tube for the three VOCs. Note that the condensation rate $\mathrm{Mr}$ increases and becomes almost stable which is well confirmed in Figure 5. In the case of the n-butanol-ethanol mixture, the n-butanol condensed vapor content is higher relative to the ethanol vapor content (Figure 6), this is due to the saturation temperature of ethanol $\left(40.35^{\circ} \mathrm{C}\right.$. $)$ which is higher than that of n-butanol $\left(38.9^{\circ} \mathrm{C}\right)$. It is also noted that the n-butanol vapor condenses slightly better in the ternary n-butanol-propanol-air $(\mathrm{Mr}=85 \%)$ relative to the ternary $\mathrm{n}$-butanol ethanol-air $(\mathrm{Mr}=84 \%)$, this is explained by the density of butanolpropanol $\left(1.34 \mathrm{Kg} . \mathrm{m}^{-3}\right)$ which is slightly higher than that of $\mathrm{n}$ butanol-ethanol $\left(1.27 \mathrm{Kg} \cdot \mathrm{m}^{-3}\right)$. In the ethanol-propanol mixture, with the same amount of vapor introduced, propanol condenses better than ethanol because of its low saturation pressure $\left(\mathrm{P}_{\mathrm{sat}}=15.7 \mathrm{KPa}\right)$ relative to that of ethanol $\left(\mathrm{P}_{\text {sat }}=20.5\right.$ $\mathrm{KPa})$.
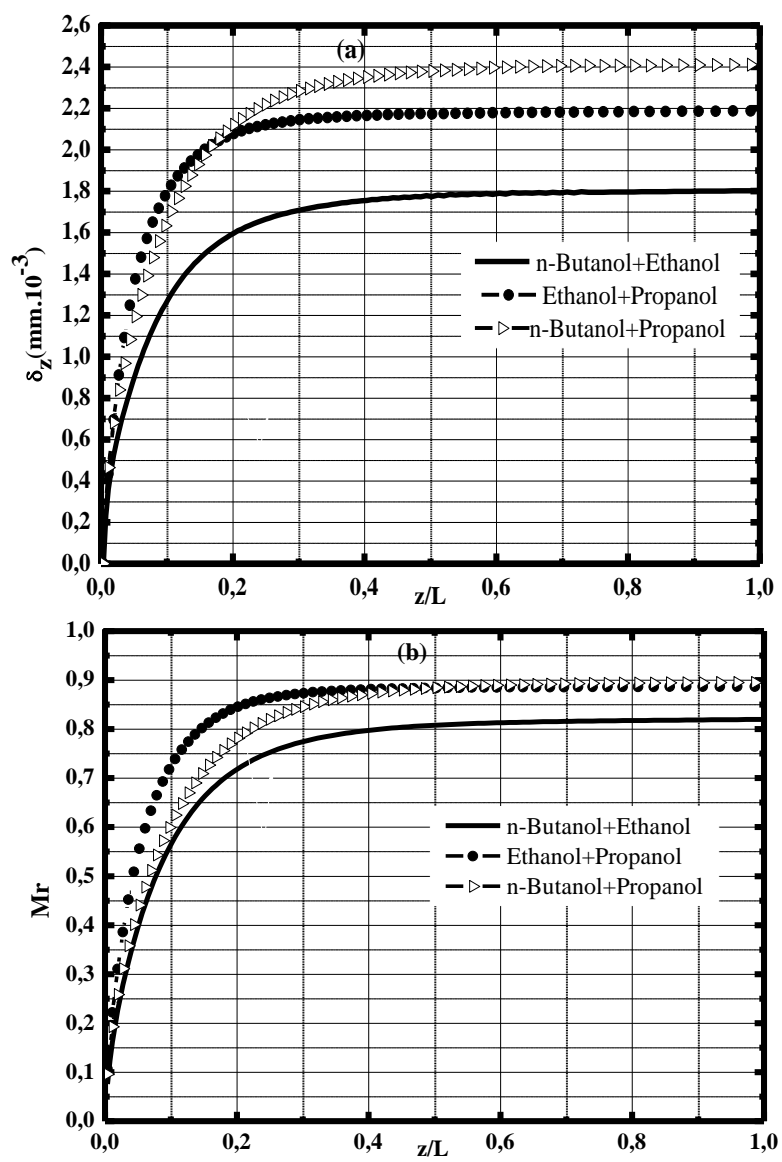

Figure 5. Variation of film liquid thickness (a) condensation rate (b) along the tube for the three mixtures

\section{CONCLUSION}

The analysis presented in this paper, has been developed to investigate the volatile organic compound condensation for various ternary vapor mixtures in the presence of air as a noncondensable gas. The calculations made it possible to determine along the tube, the bulk mass fraction, the film liquid thickness, the Nusselt number, the mixture condensation rate and of each constituent.

The main conclusions regarding performance show that:

- Transfers are therefore more intense at the inlet of tube for the three VOCs thus favoring thermal and mass exchanges.

- The Nusselt number is more significant at the inlet, which will gradually decrease until the exit where the three curves meet at the end of condensation.

- The Nusselt number is higher for the ethanol-propanol mixture compared to other VOCs.

- The condensation rate of the ethanol-propanol-air mixture is favored at the inlet of the tube.

- n-butanol vapor condenses better in the ternary n-butanolpropanol-air compared to ternary n-butanol-ethanol.

To deepen this research, we suggest some perspectives in this direction:

- The elaborate model can be extended to the turbulent regime. Considering other binary or ternary mixtures.

- Modeling of condensation in horizontal or inclined 
systems with porous walls.
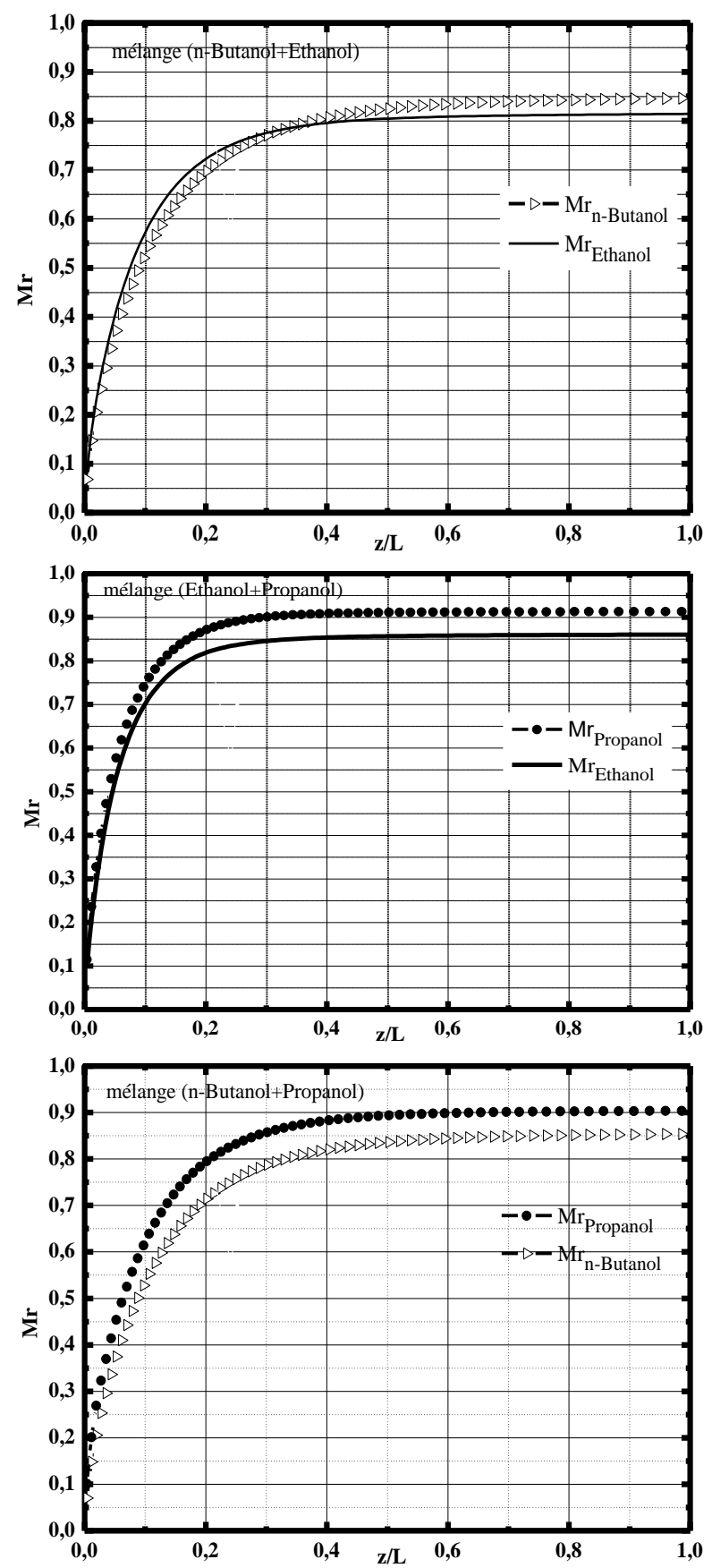

Figure 6. Variation of the condensation rate along the tube for each mixture

\section{REFERENCES}

[1] Toor, H.L. (1957). Diffusion in three component gas mixtures. AIChE Journal, 3(2): 198-207. https://doi.org/10.1002/aic.690030214

[2] Mirkovich, V.V., Missen, R.W. (1961). Non-film wise condensation of binary vapors of miscible liquids. Canadian Journal of Chemical Engineering, 86-87.

[3] Mirkovich, V.V., Missen, R.W. (1963). A study of the condensation of bilary vapors of miscible liquids. Canadian Journal of Chemical Engineering, 73-78.

[4] Bandrowski, J., Bryczkowski, A. (1975). Experimental study of heat transfer at the total condensation of mixed vapours of miscible liquids. Int. Journal of Heat and Mass Transfer, 18(4): 503-512. https://doi.org/10.1016/0017-9310(75)90291-4

[5] Taitel, Y., Tamir, A. (1974). Film condensation of multicomponent mixtures. International Journal of Multiphase Flow, 1(5): 697-714. https://doi.org/10.1016/0301-9322(74)90026-3

[6] Braun, M., Renz, U. (1997). Multicomponent diffusion interaction during condensation in laminar and turbulent pipe flow. International Journal of Heat and Mass Transfer, 40(1): 131-139. https://doi.org/10.1016/S00179310(96)00083-X

[7] Fujii, T., Koyama, S.H., Ndiwalana, N.M., Nakamura, Y. (1990). Experimental study of gravity controlled condensation of binary vapor mixtures on a smooth horizontal tube. $91 \mathrm{~h}$ International Heat Transfer Conference, pp.

https://doi.org/10.1615/IHTC9.3780

109-114.

[8] El Hammami, Y., Azzabakh, A., Mir, R., Mediouni, T. (2013). Étude numérique de la condensation d'un mélange ternaire en film liquide à l'intérieur d'un tube vertical. 16th International Conference of Thermal (Jith), Marrakech (Morocco).

[9] Zine-Dine, K., El Hammami, Y., Mir, R., Mediouni, T., Armou, S. (2017). Effect of the non condensable gas type during condensation of water vapor. Thermal Science, International Scientific Journal, 21(6A): 2451-2462. https://doi.org/10.2298/TSCI160612294Z

[10] Hassaninejadfarahani, F., Guyot, M.K., Ormiston, S.J. (2014). Numerical analysis of mixed convection laminar film condensation from high air mass fraction steam-air mixtures in vertical tubes. International Journal of Heat and Mass Transfer, 78: 170-180. https://doi.org/10.1016/j.ijheatmasstransfer.2014.06.047

[11] Lebedev, P.D., Baklastov, A.M., Sergazin, F.Z. (1969). Aerodynamics heat and mass transfer in vapour condensation from humid air on a flat plate in a longitudinal flow in asymmetrically cooled slot. International Journal of Heat and Mass Transfer, 12: 833-841. https://doi.org/10.1016/0017-9310(69)901501

[12] Fuller, E.N. (1966). Ind. Eng. Chem. 58(5): 19. McGrawHill New York.

[13] Perry Don, R.H. (1999). Perry's Chemical Engineers Handbook Chp: Prediction and correlation of physical properties 2-337. McGraw-Hill New York. https://doi.org/10.1036/0071422943

[14] Bromley, S.W., Wilke, C.R. (1951). Ind. Eng. Chem. 43(7): 1641-1648. https://doi.org/10.1021/ie50499a046

[15] Patankar, S.V. (1980). Numerical Heat Transfer and Fluid Flow. Hemisphere/Mc Graw-Hill, New York.

[16] Raithby, G.D., Schneider, G.E. (1980). Numerical solutions of problems in incompressible fluid flow: Treatment of the velocity-pressure coupling. Numerical Heat Transfer, 2: 417-440. https://doi.org/10.1080/10407787908913423

[17] Nougier, J.P. (1991). Numerical calculation method. $3^{\text {nd }}$ Ed. Paris, Madsson.

\section{NOMENCLATURE}

$\mathrm{C}_{\mathrm{p}} \quad$ specific heat, $\mathrm{J} . \mathrm{kg}^{-1} \cdot \mathrm{K}^{-1}$

$\mathrm{D}_{\mathrm{m}} \quad$ diffusion coefficient, $\mathrm{m}^{2} \cdot \mathrm{s}^{-1}$

d diameter of tube $(\mathrm{d}=2 \mathrm{R}), \mathrm{m}$ 
g gravity acceleration, $\mathrm{m} \cdot \mathrm{s}^{-2}$

$\mathrm{Hr}$ relative humidity, $\%$

$h_{e} \quad$ coefficient of external convection fluidwall, W. $\mathrm{m}^{-2} \cdot \mathrm{K}^{-1}$

$\mathrm{h}_{\mathrm{fg}} \quad$ latent heat of vaporization, $\mathrm{J}_{\mathrm{K}} \mathrm{Kg}^{-1}$

$\mathrm{h}_{\mathrm{M}} \quad$ coefficient of mass transfer, $\mathrm{m} . \mathrm{s}^{-1}$

$\mathrm{h}_{\mathrm{t}} \quad$ coefficient de heat transfer, $\mathrm{W} \cdot \mathrm{m}^{-2} \cdot \mathrm{K}^{-1}$

$\mathrm{L} \quad$ length of tube, $\mathrm{m}$

$\mathrm{m}_{\mathrm{I}} \quad$ mass flux at the interface, $\mathrm{Kg} \cdot \mathrm{m}^{-2} \cdot \mathrm{s}^{-1}$

$\mathrm{m}_{\text {in }} \quad$ gas mass flow, $\mathrm{Kg} \cdot \mathrm{m}^{-2} \cdot \mathrm{s}^{-1}$

$\mathrm{M}_{\mathrm{nc}}$ molar mass of non-condensable gas, $\mathrm{Kg} . \mathrm{Kmol}^{-1}$

$\mathrm{Mr} \quad$ condensate mass rate

$\mathrm{P}_{\text {in }} \quad$ inlet pressure, $\mathrm{Pa}$

$\mathrm{P}_{\mathrm{d}} \quad$ dynamic pression, $\mathrm{Pa}$

$\mathrm{Q}_{\mathrm{I}}$ total heat flux, W.m-2

Q Lat latent heat flux, W. $\mathrm{m}^{-2}$

Qsen sensible heat flux, W.m ${ }^{-2}$

$\mathrm{Q}_{\mathrm{w}} \quad$ heat flow to wall, W. $\mathrm{m}^{-2}$

$\mathrm{r}$ radial co-ordinate, $\mathrm{m}$

$\mathrm{R}$ radius of tube, $\mathrm{m}$

$\mathrm{T}_{\text {bulk }} \quad$ bulk temperature, $\mathrm{K}$

$\mathrm{T}_{\mathrm{e}} \quad$ external fluid temperature, $\mathrm{K}$

$\mathrm{T}_{\mathrm{W}} \quad$ wall temperature, $\mathrm{K}$

$\Delta \mathrm{T}$ difference temperature $\left(\mathrm{T}_{\mathrm{in}}-\mathrm{T}_{\mathrm{e}}\right), \mathrm{K}$

$\mathrm{u} \quad$ velocity in the $\mathrm{z}$-direction, $\mathrm{m} . \mathrm{s}^{-1}$ $\mathrm{u}^{*} \quad$ dimensionless Velocity in the $\mathrm{z}$-direction,

$\mathrm{u} / \mathrm{u}_{\mathrm{in}}$

$\mathrm{v} \quad$ velocity in the r-direction, $\mathrm{m} \cdot \mathrm{s}^{-1}$

$\mathrm{W} \quad$ vapor mass Fraction

$\mathrm{W}_{\mathrm{nc}} \quad$ non condensable gas mass fraction

$\mathrm{W}^{*}$ dimensionless vapor mass fraction, $\mathrm{W} / \mathrm{W}_{\text {in }}$

$\mathrm{z} \quad$ axial co-ordinate, $\mathrm{m}$

$\mathrm{Z}^{*} \quad$ dimensionless axial co-ordinate, $\mathrm{z} / 2 \mathrm{R}$

\section{Greek symbols}

$\delta \quad$ film liquid thickness, $\mathrm{m}$

$\rho \quad$ Density, Kg.m ${ }^{-3}$

$\eta \quad$ adimensional radial coordinate

$\mu \quad$ dynamic viscosity, $\mathrm{Kg} \cdot \mathrm{m}^{-1} \cdot \mathrm{s}^{-1}$

$\lambda$ thermal conductivity, W. $\mathrm{m}^{-1} \cdot \mathrm{K}^{-1}$

\section{Subscripts}

e extern

g gas

I interface condition liquid-gas

in Inlet condition

$1 \quad$ liquid

m mixture

w wall 